\title{
Non-linear association of plasma level of high-density lipoprotein cholesterol with endobronchial biopsy bleeding in patients with lung cancer
}

\author{
Saibin Wang ${ }^{1 *}$, Jingcheng Zhang ${ }^{2}$ and Xiaodong $\mathrm{Lu}^{3^{*}}$
}

\begin{abstract}
Background: Despite a large body of studies have demonstrated the multifaceted behavior of high-density lipoproteins (HDLs) in several physiological and pathological processes, the levels of plasma HDL-cholesterol (HDLC) that may be associated with endobronchial biopsy (EBB)-related bleeding have never been examined.

Methods: We conducted a single-center retrospective cohort study of 628 consecutive patients with primary lung cancer who had undergone EBB at a large tertiary hospital between January 2014 and February 2018. Patients were divided into the bleeding group and the non-bleeding group according to the bronchoscopy report. The association between HDL-C levels and EBB-induced bleeding was evaluated using the LASSO regression analysis, multiple regression analysis and smooth curve fitting adjusted for potential confounders.

Results: There was an inverse association of plasma HDL-C concentration with the incidence of EBB-induced bleeding as assessed by univariate analysis $(P<0.05)$. However, in piecewise linear regression analysis, a non-linear relationship with threshold saturation effects was observed between plasma HDL-C concentrations and EBB-induced bleeding. The incidence of EBB-induced bleeding decreased with $\mathrm{HDL}-\mathrm{C}$ concentrations from $1.5 \mathrm{mmol} / \mathrm{L}$ up to $2.0 \mathrm{mmol} / \mathrm{L}$ (adjusted $\mathrm{OR}, 0.39 ; 95 \% \mathrm{Cl}, 0.20-0.74)$, but increased with HDL-C levels above the inflection point (HDL-C $=2.0 \mathrm{mmol} / \mathrm{L}$ ).

Conclusions: There was a non-linear association between plasma HDL-C concentrations and the risk of EBB-induced bleeding in patients with lung cancer. The plasma level of HDL-C above $2.0 \mathrm{mmol} / \mathrm{L}$ or below $1.5 \mathrm{mmol} / \mathrm{L}$ may increase the risk of EBB-induced bleeding.
\end{abstract}

Keywords: High-density lipoprotein, Lung cancer, Endobronchial biopsy, Bleeding

\section{Background}

Bronchoscopy is often required in patients with lung cancer, especially in their histopathological diagnosis [1]. However, worthy of note, biopsy-induced bleeding is frequently encountered during bronchoscopy, and massive bleeding in the airway could be life-threatening $[2,3]$. Endobronchial biopsy (EBB), one of the most widely used transbronchial biopsy modalities, has been used in the diagnosis of pulmonary disease for more than 40

\footnotetext{
* Correspondence: saibinwang@hotmail.com; xiaodongau@126.com

${ }^{1}$ Department of Respiratory Medicine, Jinhua Municipal Central Hospital, No. 365, East Renmin Road, Jinhua, Zhejiang Province 321000, China

${ }^{3}$ Department of Laboratory Medicine, Jinhua Municipal Central Hospital, No.

365, East Renmin Road, Jinhua, Zhejiang Province 321000, China

Full list of author information is available at the end of the article
}

years [4]. Reportedly, the incidence of EBB-induced bleeding is relatively high, even over $30.0 \%$ in patients with lung cancer [5].

With regard to risk factors for bleeding during bronchoscopy, mechanical ventilation, immunosuppressive state, thrombocytopenia or anti-platelet therapy, anti-coagulant drugs use, liver and kidney disorders, heart function failure, and severe pulmonary arterial hypertension were proposed by several studies [6-8]. Nevertheless, whether these factors are in reality associated with bleeding during $\mathrm{EBB}$, remain controversial $[9,10]$. On the other hand, most individuals who are subjected to EBB do not have the aforementioned factors in clinical practice.

(c) The Author(s). 2019 Open Access This article is distributed under the terms of the Creative Commons Attribution 4.0 International License (http://creativecommons.org/licenses/by/4.0/), which permits unrestricted use, distribution, and 
High-density lipoproteins (HDLs), traditionally known for its multiple protective effects on cardiovascular diseases, such as anti-atherosclerotic, anti-oxidative, anti-inflammatory and immune-modulating [11, 12], has been found to be associated with some hemorrhagic diseases in recent years [13-15]. Since factors affecting the risk of EBB-induced bleeding remain unclear, we hypothesized that plasma HDL-C may be associated with EBB-induced bleeding and had the potential to be a biomarker for EBB-induced bleeding. Therefore, we conducted this study to explore the association of plasma HDL-C with EBB-induced bleeding risk in patients with lung cancer.

\section{Methods}

\section{Study population}

This retrospective cohort study was based on 628 consecutive lung cancer patients who underwent EBB between January 2014 and February 2018 at the Jinhua Hospital of Zhejiang University, Jinhua, China. All included patients met the following criteria: a. age $\geqq 18$ years; b. local exophytic lesions located in tracheobronchial; and c. pathological diagnosis of primary lung cancer. Patients with any of the following factor were excluded, including active bleeding, platelets count $<50 \times 10^{3} / \mu \mathrm{l}$ or continuous anti-platelet therapy, continuous anti-coagulant drug use, severe liver or kidney disorders, heart function failure, mechanical ventilation, and immunosuppressive state.

Patients were divided into two groups based on the biopsy results. Specifically, patients received hemostasis maneuvers during EBB were classified to the bleeding group $(n=232)$; whereas those who did not need hemostasis maneuvers or did not experience hemorrhage during EBB were classified to the non-bleeding group $(n=396)$. Hemostasis maneuvers during EBB included endobronchial perfusion using $4{ }^{\circ} \mathrm{C}$ physiological saline or/and diluted adrenalin (1:10000), and argon plasma coagulation application.

The following characteristics of the study participants were collected: age, sex, smoking (yes or no), lesions location (the trachea, left main bronchi, right main bronchi, and right middle bronchus were classified as central airways; whereas the left lobar bronchi and the right lobar bronchi were classified as peripheral bronchi), histological types of lung cancer (adenocarcinoma, squamous cell carcinoma, small-cell lung carcinoma, and the other types), TNM stage (stage I and II was considered as early stage; stage III and IV was considered as advanced stage), and comorbidities, including chronic obstructive pulmonary disease (COPD), coronary heart disease (CHD), hypertension, and diabetes mellitus. The following blood tests (performed on admission, prior to EBB) were collected: high density lipoprotein cholesterol (HDL-C), low density lipoprotein cholesterol (LDL-C), total cholesterol (TC), triglyceride, apolipoprotein E, apolipoprotein B, white blood cell counts, C-reactive protein (CRP), neutrophil counts, hemoglobin, platelet counts, prothrombin time (PT), activated partial thromboplastin time (APTT), alanine aminotransferase (ALT), and aspartate aminotransferase (AST).

This study was approved by the ethics committee of Jinhua Hospital of Zhejiang University, Jinhua, China. All patients' information was anonymous preceding the analysis, and the requirement for informed consent, therefore, was waived.

\section{Biopsy procedures}

All procedures were performed under general anesthesia. Propofol was used for induction $(1.0 \mathrm{mg} / \mathrm{kg})$ and maintenance $(3.0-6.0 \mathrm{mg} / \mathrm{kg} / \mathrm{h})$, and remifentanil $(5.0-10.0 \mu \mathrm{g} / \mathrm{kg} /$ h) was used for sedation and analgesia. During bronchoscopy, a laryngeal mask airway (Well Lead Medical Co., Ltd., Guangzhou, China) was used, and patients underwent transorally bronchoscopy. Bronchoscopy (BF-1 T60, Olympus Corp., Tokyo, Japan) procedures were performed on all patients by two experienced bronchoscopists. Three to five biopsies were generally performed at the same location of the endobronchial lesion by forceps biopsies [16]; however, in a small number of patients, we performed only one biopsy because lesions bled significantly following the first biopsy attempt.

\section{Statistical analysis}

Patients' baseline characteristics were summarized. Age and blood test values were presented as median (Q1-Q3), and categorical variables were presented as a number and percentage. Unpaired $t$-tests (normal distribution) or Kruskal-Wallis rank sum test (non-normal distribution), Pearson chi-squared tests or the Fisher's exact, were tested between two groups for comparison, when appropriate. The least absolute shrinkage and selection operator (LASSO) regression method was employed to assess the strength of association between plasma HDL-C and EBB-induced bleeding. Multiple regression analysis was used to estimate the independent relationship between HDL-C levels and EBB-induced bleeding risk, with and without adjustment for potential confounders. We also used piecewise linear regression to test the threshold effect of HDL-C on EBB-induced bleeding together with a smoothing function. In this study, the adjusted criteria I included variables producing a change in the regression coefficient greater than $10 \%$ after introduction into the basic model or removing from the complete model (smoking, histological types, stage, triglyceride, PT, APTT and CRP); the screening criteria II included variables in criteria $I$, the regression coefficient of co-variable to dependent variable of $P<0.1$ (lesions location and neutrophils), and judged by clinical 
significance (sex, age, and apolipoprotein E). All analyses were performed using $\mathrm{R}$ software (The $\mathrm{R}$ Foundation; https://www.r-project.org/). A value of $P<0.05$ was considered statistically significant.

\section{Results}

Of 628 consecutive patients, 232 (36.9, 95\% confidence interval [CI], 33.2-40.7\%) received hemostasis maneuvers following $\mathrm{EBB}\left(4{ }^{\circ} \mathrm{C}\right.$ physiological saline or/and diluted adrenalin endobronchial perfusion, or argon plasma coagulation). No patient died of severe blood loss after a biopsy. Patients' baseline characteristics and blood tests are shown in Table 1.

In univariate analysis, the plasma HDL-C concentrations were lower in the bleeding group compared to those in the non-bleeding group (Table $2, P<0.05$ ). In addition, lesions location, histological types, TNM stage of cancer, smoking, CRP, and APTT were associated with EBB-induced bleeding (Table 2). Based on non-zero coefficients in the LASSO regression analysis (Fig. 1), seven variables were filtered. These variables (coefficient) were HDL-C (-0.0527), APTT (-0.0146), neutrophils (0.0024), CRP (0.0015), lesion location (0.6728), TNM stage $(-0.3905)$ and histological types $(-0.4902)$, among which the absolute value of coefficient of HDL-C was the maximum in all blood variables, suggesting that HDL-C has a stronger association with EBB-induced bleeding.

The association between plasma HDL-C and EBB-induced bleeding risk was shown in Table 3 after adjusting for smoking, histological type, stage of cancer, triglyceride, PT, APTT and CRP (adjust criterion I), or after adjusting for sex, age, smoking, location of lesion, histological type, stage of cancer, triglyceride, apolipoprotein E, PT, APTT, neutrophils and CRP (adjust criterion II). In piecewise analysis, we found that middle concentrations of HDL-C $(1.5-2.0 \mathrm{mmol} / \mathrm{L})$ associated with a decreased risk of EBB-induced bleeding when compared to lower concentrations $(<1.5 \mathrm{mmol} / \mathrm{L})$ (odds ratio $[\mathrm{OR}], 0.39 ; 95 \% \mathrm{CI}, 0.20-0.74 ; P<0.05)$. However, higher concentrations of HDL-C ( $\geqq 2.0 \mathrm{mmol} / \mathrm{L})$ did not associate with a decreased incidence of EBB-induced bleeding (OR, 1.63; 95\% CI, 0.51-5.22; $P>0.05$ ).

A non-linear relationship between plasma HDL-C levels and the risk of EBB-induced bleeding was observed in the smooth curve fitting (Fig. 2). Two threshold values (inflection point $\mathrm{I}=1.4 \mathrm{mmol} / \mathrm{L}$, and inflection point $\mathrm{II}=1.9 \mathrm{mmol} / \mathrm{L}$ ) were detected between plasma HDL-C levels and EBB-induced bleeding risk in two-piecewise linear regression analysis (Table 4).

\section{Discussion}

Our findings showed a statistically significant non-linear association between HDL-C level and risk of bleeding
Table 1 Baseline characteristics and blood tests of the study participants

\begin{tabular}{|c|c|}
\hline Characteristics & Values \\
\hline Age (year), median (Q1-Q3) & $65(59-70)$ \\
\hline Male, n (\%) & $487(77.5)$ \\
\hline Smoking, n (\%) & $394(62.7)$ \\
\hline Biopsy bleeding, n (\%) & $232(36.9)$ \\
\hline \multicolumn{2}{|l|}{ Location of lesion, n (\%) } \\
\hline Peripheral bronchi & $548(87.3)$ \\
\hline Central airway & $80(12.7)$ \\
\hline \multicolumn{2}{|l|}{ Stage, n (\%) } \\
\hline Early & $343(54.6)$ \\
\hline Advanced & $285(45.4)$ \\
\hline \multicolumn{2}{|l|}{ Histological types, n (\%) } \\
\hline Adenocarcinoma & $171(27.2)$ \\
\hline Squamous cell carcinoma & $313(49.8)$ \\
\hline SCLC & $111(17.7)$ \\
\hline Others & $33(5.3)$ \\
\hline \multicolumn{2}{|l|}{ Coexisting diseases, n (\%) } \\
\hline COPD & $42(6.7)$ \\
\hline Hypertension & $155(24.7)$ \\
\hline Diabetes & $32(5.1)$ \\
\hline $\mathrm{CHD}$ & $20(3.2)$ \\
\hline \multicolumn{2}{|l|}{ Blood tests, median (Q1-Q3) } \\
\hline Triglyceride (mmol/L) & $1.0(0.8-1.4)$ \\
\hline $\mathrm{TC}(\mathrm{mmol} / \mathrm{L})$ & $4.1(3.5-4.8)$ \\
\hline $\mathrm{HDL}-\mathrm{C}(\mathrm{mmol} / \mathrm{L})$ & $1.1(0.9-1.3)$ \\
\hline LDL-C (mmol/L) & $2.8(2.3-3.3)$ \\
\hline Apo E (mg/dL) & $3.6(2.8-4.6)$ \\
\hline Apo B $(g / L)$ & $1.0(0.8-1.2)$ \\
\hline Homocysteine $(\mu \mathrm{mol} / \mathrm{L})$ & $13.2(10.7-16.2)$ \\
\hline WBC $\left(\times 10^{9} / \mathrm{L}\right)$ & $6.8(5.5-8.6)$ \\
\hline Neutrophils $\left(\times 10^{9} / \mathrm{L}\right)$ & $4.6(3.5-6.4)$ \\
\hline Hemoglobin (g/L) & $128(116-139)$ \\
\hline Platelets $\left(\times 10^{9} / \mathrm{L}\right)$ & $224(172-280)$ \\
\hline CRP (mg/L) & $7.7(1.4-31.1)$ \\
\hline PT (S) & $13.0(12.3-13.6)$ \\
\hline APTT (S) & $35.1(31.8-38.5)$ \\
\hline ALT (IU/L) & $17.0(12.0-25.0)$ \\
\hline AST (IU/L) & $23.0(19.0-28.0)$ \\
\hline
\end{tabular}

SCLC Small-cell lung carcinoma; COPD Chronic obstructive pulmonary disease; CHD Coronary heart disease; TC Total cholesterol; HDL-C High density lipoprotein cholesterol; LDL-C Low density lipoprotein cholesterol; Apo, apolipoprotein; WBC White blood cell; CRP C-reactive protein; PT Prothrombin time; APTT Activated partial thromboplastin time; ALT Alanine aminotransferase; AST Aspartate aminotransferase 
Table 2 Univariate analysis of possible influencing factors of the risk of EBB-induced bleeding

\begin{tabular}{|c|c|c|}
\hline \multirow[t]{2}{*}{ Variables } & \multicolumn{2}{|c|}{ EBB-induced Bleeding } \\
\hline & OR $(95 \% \mathrm{Cl})$ & $P$ value \\
\hline Age (year) & $1.01(0.99,1.03)$ & 0.2029 \\
\hline \multicolumn{3}{|l|}{ Sex } \\
\hline Female & Ref. & \\
\hline Man & $1.33(0.89,1.98)$ & 0.1609 \\
\hline \multicolumn{3}{|l|}{ Smoking } \\
\hline No & Ref. & \\
\hline Yes & $1.45(1.03,2.04)$ & 0.0337 \\
\hline \multicolumn{3}{|l|}{ Location of lesion } \\
\hline Central airway & Ref. & \\
\hline Peripheral bronchi & $0.32(0.20,0.51)$ & $<0.0001$ \\
\hline \multicolumn{3}{|l|}{ Stage } \\
\hline Early & Ref. & \\
\hline Advanced & $1.87(1.35,2.60)$ & 0.0002 \\
\hline \multicolumn{3}{|l|}{ Histological type } \\
\hline Adenocarcinoma & Ref. & \\
\hline Squamous cell carcinoma & $2.63(1.73,4.01)$ & $<0.0001$ \\
\hline $\mathrm{SCLC}$ & $2.14(1.27,3.61)$ & 0.0043 \\
\hline Others & $2.20(1.00,4.82)$ & 0.0488 \\
\hline \multicolumn{3}{|l|}{ COPD } \\
\hline No & Ref. & \\
\hline Yes & $1.05(0.55,2.01)$ & 0.8727 \\
\hline \multicolumn{3}{|l|}{ Hypertension } \\
\hline No & Ref. & \\
\hline Yes & $1.11(0.76,1.61)$ & 0.5995 \\
\hline \multicolumn{3}{|l|}{ Diabetes } \\
\hline No & Ref. & \\
\hline Yes & $0.89(0.42,1.88)$ & 0.7575 \\
\hline \multicolumn{3}{|l|}{ CHD } \\
\hline No & Ref. & \\
\hline Yes & $1.14(0.46,2.84)$ & 0.7736 \\
\hline Triglyceride (mmol/L) & $0.80(0.62,1.04)$ & 0.1018 \\
\hline $\mathrm{TC}(\mathrm{mmol} / \mathrm{L})$ & $0.93(0.78,1.11)$ & 0.4113 \\
\hline $\mathrm{HDL}-\mathrm{C}(\mathrm{mmol} / \mathrm{L})$ & $0.56(0.34,0.94)$ & 0.0270 \\
\hline LDL-C (mmol/L) & $0.89(0.71,1.11)$ & 0.3031 \\
\hline Apo E (mg/dL) & $0.91(0.82,1.02)$ & 0.1153 \\
\hline Apo B (g/L) & $0.80(0.45,1.42)$ & 0.4421 \\
\hline Homocysteine $(\mu \mathrm{mol} / \mathrm{L})$ & $1.00(0.98,1.02)$ & 0.8840 \\
\hline WBC $\left(\times 10^{9} / \mathrm{L}\right)$ & $1.03(0.98,1.08)$ & 0.2477 \\
\hline Neutrophils $\left(\times 10^{9} / \mathrm{L}\right)$ & $1.04(0.99,1.10)$ & 0.0937 \\
\hline Hemoglobin (g/L) & $1.00(0.99,1.01)$ & 0.4135 \\
\hline Platelets $\left(\times 10^{9} / \mathrm{L}\right)$ & $1.00(1.00,1.00)$ & 0.2392 \\
\hline CRP (mg/L) & $1.01(1.00,1.01)$ & 0.0173 \\
\hline
\end{tabular}

Table 2 Univariate analysis of possible influencing factors of the risk of EBB-induced bleeding (Continued)

\begin{tabular}{lll}
\hline Variables & \multicolumn{2}{l}{ EBB-induced Bleeding } \\
\cline { 2 - 3 } & OR $(95 \% \mathrm{Cl})$ & $P$ value \\
\hline PT (S) & $0.93(0.84,1.02)$ & 0.1220 \\
APTT (S) & $0.96(0.94,0.99)$ & 0.0180 \\
ALT (IU/L) & $1.00(0.99,1.01)$ & 0.8181 \\
AST (IU/L) & $1.00(0.99,1.01)$ & 0.9365 \\
\hline
\end{tabular}

EBB endobronchial biopsy; SCLC small-cell lung carcinoma; COPD Chronic obstructive pulmonary disease; CHD coronary heart disease; TC total cholesterol; HDL-C high density lipoprotein cholesterol; $L D L-C$ low density lipoprotein cholesterol; Apo, apolipoprotein; WBC white blood cell; CRP Creactive protein; $P T$ prothrombin time; $A P T T$ activated partial thromboplastin time; ALT alanine aminotransferase; AST aspartate aminotransferase

during EBB. Specifically, in order to reduce the risk of EBB-induced bleeding, especially for massive bleeding, it may be helpful to maintain the concentrations of plasma HDL-C within 1.5-2.0 $\mathrm{mmol} / \mathrm{L}$ prior to aggressive biopsies on endobronchial exophytic lesions in patients with lung cancer.

Bronchoscopy-related bleeding is a very common complication in clinical practice, especially when biopsies are performed. Of note, malignant lesions reportedly are more likely to bleed upon biopsy than benign mucosal lesions [17], and the incidence of massive hemorrhage increases following EBB [18]. In this scenario, a number of studies have been conducted and several risk factors that may be associated with bleeding during bronchoscopy have been proposed, such as immunosuppressive state, thrombocytopenia $\left(<50 \times 10^{3} / \mu \mathrm{l}\right)$, anti-platelet or anti-coagulant drugs use, severe liver and kidney disorders, heart function failure, severe pulmonary arterial hypertension, and lung transplant [6-8]. However, most of the aforementioned factors remain conflicting or lack supporting evidence $[9,10]$. To our knowledge, there is still no effective indicator or biomarker available for predicting bleeding risk during bronchoscopy in clinical practice.

HDLs are heterogeneous lipoproteins involve in multiple physiological and pathological processes in the human body [19]. During the last few decades, most studies conducted have demonstrated HDL-C as a protective factor in cardiovascular disease [19]. In recent year, several studies revealed that HDL-C was associated with the risk of hemorrhage in some disorders, especially in intracranial hemorrhage $[13,20]$. In this regard, several studies have shown that the risk of intracerebral hemorrhage significantly increased with decreasing HDL-C concentrations [14, 15]. However, in a meta-analysis of $1,430,141$ participants from 23 prospective studies, the inverse relationship between intracerebral hemorrhage and HDL-C was pointed out by researchers [13]. Despite the fact that the relationship between HDL-C and the risk of intracerebral hemorrhage remains controversial, these studies, at least, 

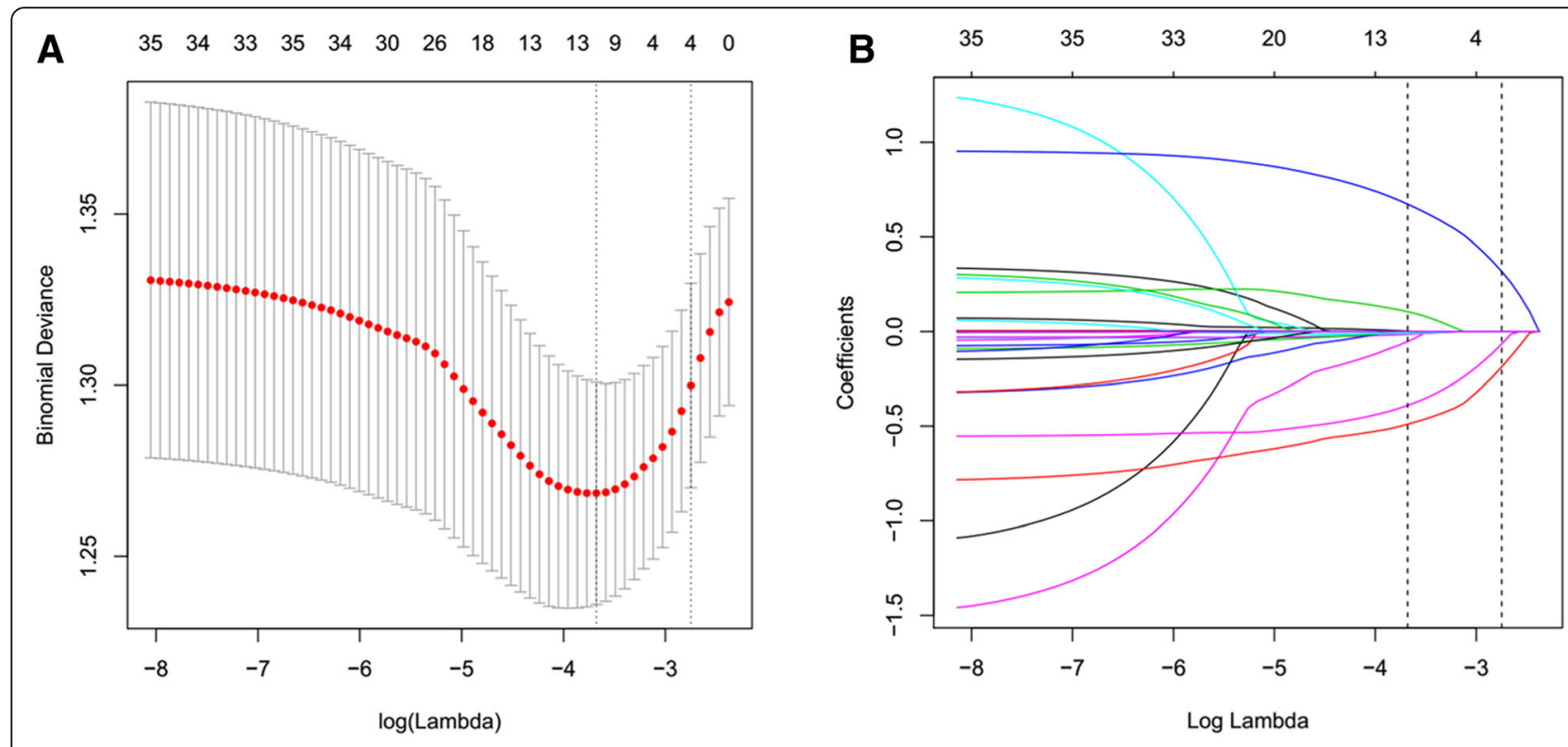

Fig. 1 The strength of association between variables with EBB-induced bleeding in the LASSO regression method. a Tuning variable (lambda) selection using 10-fold cross-validation in the LASSO regression. Dotted vertical lines were drawn at the optimal values based on the minimum criteria (left dotted line) and the 1-SE criteria (right dotted line). b A coefficient profile plot was produced against the log (lambda) sequence. In the current study, variables were filtered according to the minimum criteria (left dotted line), where optimal lambda resulted in 7 nonzero coefficients, including HDL-C (-0.0527), APTT (- 0.0146), neutrophils (0.0024), CRP (0.0015), lesion location (0.6728), TNM stage (- 0.3905) and histological types (- 0.4902). $\mathrm{SE}=$ standard error

have indicated that HDL-C may be associated with the risk of bleeding in some disorders.

The current knowledge in the realm of the effect of HDL on coagulation and clotting cascade remains lacking. Adiponectin, an adipose-derived cytokine, may partially explain the effect of HDL on coagulation. Several studies have demonstrated that, both in vitro and in vivo, HDL associates strongly with adiponectin [21-23]. Reportedly, adiponectin could affect platelet hyperactivity, hypercoagulability, and hypofibrinolysis [24-26]. It plays an anticoagulant role by increasing the expression of plasminogen activator inhibitor (PAI)-I both in human and in animal models [27-30]. Therefore, the effect of HDL on coagulation may be mediated partially through the suppressive effect of adiponectin on PAI-I production. In addition, HDL could modulate the function of vascular smooth muscle and platelets [31, 32].
The present study found that plasma HDL-C concentrations strongly associated with the incidence of EBB-induced bleeding in LASSO regression analysis, which is considered to surpass the approach of identifying variables based on the strength of their univariable association with the outcome, especially when there are a bunch of variables [33, 34]. This association still strengthened after controlling for potentially confounding variables (adjust I controlling for: smoking, histological type, stage of cancer, triglyceride, PT, APTT and CRP; adjust II controlling for: sex, age, smoking, location of lesion, histological type, stage of cancer, triglyceride, apolipoprotein E, PT, APTT, neutrophils and CRP) in in multiple regression analysis. There was a non-linear association between plasma HDL-C levels and EBB-induced bleeding risk. We further uncovered a piecewise effect of HDL-C concentrations against the risk of EBB-induced bleeding. Between $1.5-2.0 \mathrm{mmol} / \mathrm{L}$,

Table 3 Multivariate regression analysis of $\mathrm{HDL}-\mathrm{C}$ with the risk of EBB-induced bleeding

\begin{tabular}{|c|c|c|c|}
\hline \multirow[t]{2}{*}{$\mathrm{HDL}-\mathrm{C}(\mathrm{mmol} / \mathrm{L})$} & \multicolumn{3}{|c|}{ EBB-induced bleeding OR (95\% Cl) P-value } \\
\hline & Non-adjust & Adjust $\mathrm{I}^{\mathrm{a}}$ & Adjust $\|^{\mathrm{b}}$ \\
\hline$<1.5$ & Ref. & Ref. & Ref. \\
\hline $1.5-2.0$ & $0.35(0.19,0.64) 0.0007$ & $0.38(0.20,0.71) 0.0026$ & $0.39(0.20,0.74) 0.0042$ \\
\hline$\geqq 2.0$ & $1.55(0.54,4.48) 0.4187$ & $1.95(0.65,5.88) 0.2339$ & $1.63(0.51,5.22) 0.4107$ \\
\hline
\end{tabular}

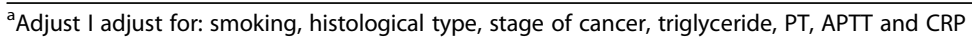

${ }^{b}$ Adjust II adjust for: sex, age, smoking, location of lesion, histological type, stage of cancer, triglyceride, apolipoprotein E, PT, APTT, neutrophils and CRP. EBB, endobronchial biopsy; HDL-C, high density lipoprotein cholesterol; PT, prothrombin time; APTT, activated partial thromboplastin time; CRP, C-reactive protein 


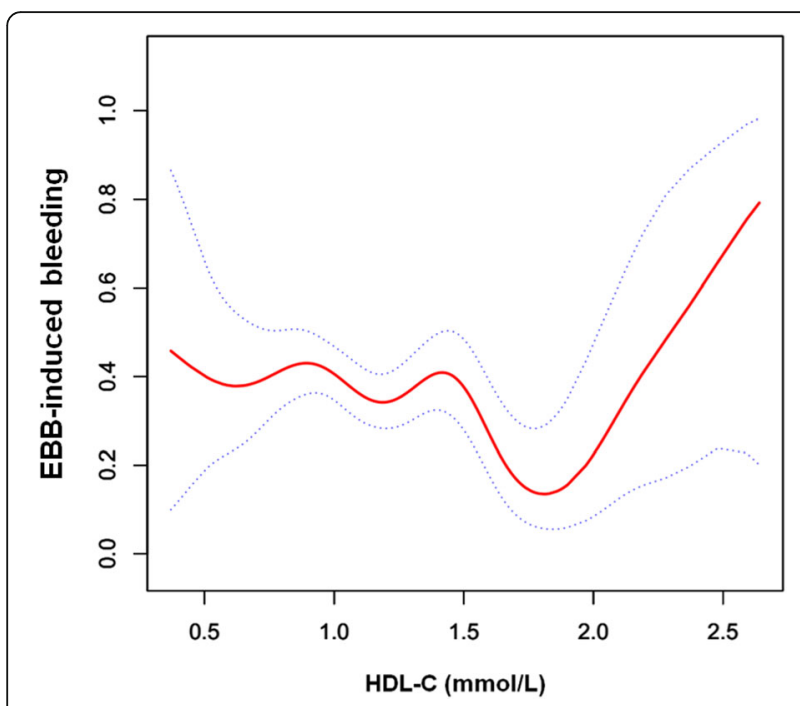

Fig. 2 A non-linear relationship with threshold effect between plasma HDL-C concentrations and EBB-induced bleeding risk in the smooth curve fitting after adjusting the potential confounding factors (sex, age, smoking, location of lesion, histological type, stage of cancer, triglyceride, apolipoprotein E, PT, APTT, neutrophils and (RP) is shown in the figure. Dotted lines represent the upper and lower 95\% confidence intervals. EBB = endobronchial biopsy; HDL-C = high density lipoprotein cholesterol; PT = prothrombin time; APTT $=$ activated partial thromboplastin time; $C R P=C$-reactive protein

HDL-C was associated with lower bleeding risk, whereas higher $(>2.0 \mathrm{mmol} / \mathrm{L})$ or lower $(<1.5 \mathrm{mmol} / \mathrm{L})$ concentrations of HDL-C were associated with increased EBB-induced bleeding risk. This finding may increase our understanding of the novel role of HDL-C.

The current study is the first to reveal the relationship between plasma HDL-C levels and EBB-induced bleeding risk during bronchoscopy. However, several limitations of the present study are worth noting. First, although we had adjusted for potentially confounding factors, this study was inevitably subject to the limitations of the use of observational data. Second, a

Table 4 Threshold effect analysis of HDL-C on EBB-induced bleeding using two-piecewise linear regression

\begin{tabular}{lll}
\hline $\begin{array}{l}\text { Inflection point of } \mathrm{HDL}-\mathrm{C} \\
\text { (mmol/L) }\end{array}$ & EBB-induced Bleeding & \\
\cline { 2 - 3 } & $\mathrm{OR}(95 \% \mathrm{Cl})$ & $P$ value \\
\hline Inflection point I & $1.03(0.42,2.51)$ & 0.9554 \\
$<1.4$ & $0.02(0.00,0.41)$ & 0.0118 \\
$>1.4$ & & \\
Inflection point II & $0.49(0.25,0.95)$ & 0.0343 \\
$<1.9$ & $19.99(0.85,470.30)$ & 0.0631 \\
$>1.9$ &
\end{tabular}

${ }^{a}$ Adjust for: sex, age, smoking, location of lesion, histological type, stage of cancer, triglyceride, apolipoprotein E, PT, APTT, neutrophils and CRP. EBB, endobronchial biopsy; HDL-C, high density lipoprotein cholesterol; PT, prothrombin time; APTT, activated partial thromboplastin time; CRP, C-reactive protein quantitative measurement of the volume of EBB-induced bleeding in our study was unavailable. It remains challenging to accurately measure bleeding during bronchoscopy [35]. Therefore, the grouping of biopsy bleeding may not be accurate in this study because we divided participants into a bleeding group or a non-bleeding group based only on whether they received hemostasis during EBB. Third, we only collected HDL-C concentrations at admission, and repeated measurements were unavailable in the retrospective data. Therefore, further validation in prospective studies is warranted. Despite these limitations, this study has notable clinical implications since no effective indicator for EBB-induced bleeding has been found to date.

\section{Conclusions}

This study revealed that plasma HDL-C levels are associated with EBB-induced bleeding risk in a non-linear pattern in patients with lung cancer, and the relative safe concentrations of plasma HDL-C on EBB bleeding may be $1.5-2.0 \mathrm{mmol} / \mathrm{L}$. This finding highlights the importance of HDL-C concentrations on EBB and may have implications for bleeding risk assessment and risk modification prior to EBB. Future studies are needed to fully evaluate the effect of HDL-C on EBB-induced bleeding and investigate the underlying mechanisms.

\section{Abbreviations}

ALT: Alanine aminotransferase; APC: Argon plasma coagulation; APTT: Activated partial thromboplastin time; AST: Aspartate aminotransferase: CHD: Coronary heart disease; Cl: Confidence interval; COPD: Chronic obstructive pulmonary disease; CRP: C-reactive protein; EBB: Endobronchial biopsy; HDL-C: High density lipoprotein cholesterol; LASSO: The least absolute shrinkage and selection operator; LDL-C: Low density lipoprotein cholesterol; OR: Odds ratio; PAl: Plasminogen activator inhibitor; PT: Prothrombin time; TC: Total cholesterol; WBC: White blood cell

\section{Acknowledgements}

We appreciate the help and support of all the participants involved in the study.

\section{Funding}

This study was supported by the Medical and Health Science and Technology Plan Project of Zhejiang Province (No. 2018 RC079 to S. W.), the Youth Research Fund of Jinhua Hospital of Zhejiang University (No. JY2017205 to S. W.), the Science and Technology Key Project of Jinhua City (No. 20163011 to S. W.), and the Chinese Medicine Science and Technology project of Jinhua City (No. 2017jzk05 to S. W)

\section{Availability of data and materials}

The datasets used and/or analyzed during the current study are available from the corresponding author on reasonable request.

\section{Authors' contributions}

S. W. contributed substantially to the study design, data analysis and interpretation, the writing of the manuscript, and takes responsibility for the integrity of the data and the accuracy of the data analysis. J. Z. and X. L. contributed to data collection, data analysis, data interpretation, and manuscript revision. 


\section{Ethics approval and consent to participate}

This study was approved by the ethics committee of Jinhua Hospital of Zhejiang University. The requirement for informed consent was waived because the data were handled anonymously.

\section{Competing interests}

The authors declare no conflicts of interests.

\section{Consent for publication}

Not applicable.

\section{Publisher's Note}

Springer Nature remains neutral with regard to jurisdictional claims in published maps and institutional affiliations.

\section{Author details}

'Department of Respiratory Medicine, Jinhua Municipal Central Hospital, No. 365, East Renmin Road, Jinhua, Zhejiang Province 321000, China. ${ }^{2}$ Department of Hematology, Jinhua Municipal Central Hospital, No. 365, East Renmin Road, Jinhua, Zhejiang Province 321000 , China. ${ }^{3}$ Department of Laboratory Medicine, Jinhua Municipal Central Hospital, No. 365, East Renmin Road, Jinhua, Zhejiang Province 321000, China.

Received: 28 June 2018 Accepted: 6 January 2019

Published online: 18 January 2019

\section{References}

1. Rivera MP, Mehta AC, Wahidi MM. Establishing the diagnosis of lung cancer: diagnosis and management of lung cancer, 3rd ed: American College of Chest Physicians evidence-based clinical practice guidelines. Chest. 2013; 143:e142S-65S

2. Herth FJF. Bronchoscopy and bleeding risk. Eur Respir Rev. 2017;26:170052

3. Chinsky K. Bleeding risk and bronchoscopy: in search of the evidence in evidence-based medicine. Chest. 2005;127:1875-7.

4. Fallon J, Medford ARL. Endobronchial and transbronchial biopsy experience: a United Kingdom survey. Thorac Cancer. 2017:8:291-5.

5. Wang $S, Y e$ Q, Tu J, Song Y. The location, histological type and stage of lung cancer are associated with bleeding during endobronchial biopsy. Cancer Manag Res. 2018;10:1251-7.

6. Herth FJ, Becker HD, Ern A. Aspirin does not increase bleeding complications after transbronchial biopsy. Chest. 2002:122:1461-4.

7. Diette GB, Wiener CM, White P Jr. The higher risk of bleeding in lung transplant recipients from bronchoscopy is independent of traditional bleeding risks: results of a prospective cohort study. Chest. 1999;115:397402.

8. Brickey DA, Lawlor DP. Transbronchial biopsy in the presence of profound elevation of the international normalized ratio. Chest. 1999;115:1667-71.

9. Carr IM, Koegelenberg CF, von Groote-Bidlingmaier F, Mowlana A, Silos K, Haverman T, Diacona AH, Bolligeret CT. Blood loss during flexible bronchoscopy: a prospective observational study. Respiration. 2012:84:312-8.

10. Zahreddine I, Atassi K, Fuhrman C. Impact of prior biological assessment of coagulation on the hemorrhagic risk of fiberoptic bronchoscopy. Rev Mal Respir. 2003;20:341-6.

11. Otocka-Kmiecik A, Mikhailidis DP, Nicholls SJ, Davidson M, Rysz J, Dysfunctional BM. HDL: a novel important diagnostic and therapeutic target in cardiovascular disease? Prog Lipid Res. 2012;51:314-24.

12. Catapano AL, Pirillo A, Bonacina F, Norata GD. HDL in innate and adaptive immunity. Cardiovasc Res. 2014;103:372-83.

13. Wang $X$, Dong Y, Qi X, Huang C, Hou L. Cholesterol levels and risk of hemorrhagic stroke: a systematic review and meta-analysis. Stroke. 2013;44: 1833-9.

14. Wang X, Li S, Bai Y, Fan X, Sun K, Wang J, Hui R. Inverse association of plasma level of high-density lipoprotein cholesterol with intracerebral hemorrhage. J Lipid Res. 2011:52:1747-54.

15. Zhang Y, Tuomilehto J, Jousilahti P, Wang Y, Antikainen R, Hu G. Total and high-density lipoprotein cholesterol and stroke risk. Stroke. 2012:43:1768-74.

16. Rivera MP, Detterbeck F, Mehta AC. Diagnosis of lung cancer: the guidelines. Chest. 2003;123:129S-36S.

17. Ozgül MA, Turna A, Yildiz P, Ertan E, Kahraman S, Yilmaz V. Risk factors and recurrence patterns in 203 patients with hemoptysis. Tuberk Toraks. 2006:54 243-8.
18. Jin F, Mu D, Chu D, Fu E, Xie Y, Liu T. Severe complications of bronchoscopy. Respiration. 2008:76:429-33.

19. Pirro M, Ricciuti B, Rader DJ, Catapano AL, Sahebkar A, Banach M. High density lipoprotein cholesterol and cancer: marker or causative? Prog Lipid Res. 2018;71:54-69.

20. Chang JJ, Katsanos AH, Khorchid Y, Dillard K, Kerro A, Burgess LG, Goyal N, Alexandrov AW, Alexandrov AV, Tsivgoulis G. Higher low-density lipoprotein cholesterol levels are associated with decreased mortality in patients with intracerebral hemorrhage. Atherosclerosis. 2018;269:14-20.

21. Cnop M, Havel PJ, Utzschneider KM, Carr DB, Sinha MK, Boyko EJ, Retzlaff BM, Knopp RH, Brunzell JD, Kahn SE. Relationship of adiponectin to body fat distribution, insulin sensitivity and plasma lipoproteins: evidence for independent roles of age and sex. Diabetologia. 2003;46:459-69.

22. Weiss R, Otvos JD, Flyvbjerg A, Miserez AR, Frystyk J, Sinnreich R, Kark JD. Adiponectin and lipoprotein particle size. Diabetes Care. 2009:32:1317-9.

23. Ocak N, Dirican M, Ersoy A, Sarandol E. Adiponectin, leptin, nitric oxide, and C-reactive protein levels in kidney transplant recipients: comparison with the hemodialysis and chronic renal failure. Ren Fail. 2016;38:1639-46.

24. Darvall KA, Sam RC, Silverman SH, Bradbury AW, Adam DJ. Obesity and thrombosis. Eur J Vasc Endovasc Surg. 2007;33:223-33.

25. Kim CK, Cho DH, Lee KS, Lee DK, Park CW, Kim WG, Lee SJ, Ha KS, Goo Taeg $\mathrm{O}$, Kwon $\mathrm{YG}$, et al. Ginseng berry extract prevents atherogenesis via antiinflammatory action by upregulating phase II gene expression. Evid Based Complement Alternat Med. 2012:490301:2012

26. Eriksson M, Johnson O, Boman K, Hallmans G, Hellsten G, Nilsson TK, Soderberg S. Improved fibrinolytic activity during exercise may be an effect of the adipocyte-derived hormones leptin and adiponectin. Thromb Res. 2008:122:701-8.

27. Hoo RL, Chow WS, Yau MH, Xu A, Tso AW, Tse HF, Fong CH, Tam S, Chan L, Lam KS. Adiponectin mediates the suppressive effect of rosiglitazone on plasminogen activator inhibitor-1 production. Arterioscler Thromb Vasc Biol. 2007;27:2777-82.

28. Lowe GD, Danesh J, Lewington S, Walker M, Lennon L, Thomson A, Rumley A, Whincup PH. Tissue plasminogen activator antigen and coronary heart disease: prospective study and meta-analysis. Eur Heart J. 2004:25:252-9.

29. Goldberg RB, Temprosa M, Mele L, Orchard T, Mather K, Bray G, Horton E, Kitabchi A, Krakoff J, Marcovina S, et al. Change in adiponectin explains most of the change in HDL particles induced by lifestyle intervention but not metformin treatment in the diabetes prevention program. Metabolism. 2016;65:764-75

30. Raiko JR, Oikonen M, Wendelin-Saarenhovi M, Siitonen N, Kähönen M, Lehtimäki T, Viikari J, Jula A, Loo BM, Huupponen R, et al. Plasminogen activator inhitor-1 associates with cardiovascular risk factors in healthy young adults in the cardiovascular risk in young Finns study. Atherosclerosis. 2012;224:208-12.

31. Naqvi TZ, Shah PK, Ivey PA, Molloy MD, Thomas AM, Panicker S, Ahmed A Cercek B, Kaul S. Evidence that high-density lipoprotein cholesterol is an independent predictor of acute plateletdependent thrombus formation. Am J Cardiol. 1999:84:1011-7.

32. Mineo C, Shaul PW. Novel biological functions of high-density lipoprotein cholesterol. Circ Res. 2012;111:1079-90.

33. Huang YQ, Liang CH, He L, Tian J, Liang CS, Chen X, Ma ZL, Liu ZY. Development and validation of a radiomics nomogram for preoperative prediction of lymph node metastasis in colorectal cancer. J Clin Oncol. 2016:34:2157-64.

34. Tibshirani R. The lasso method for variable selection in the cox model. Stat Med. 1997:16:385-95.

35. Schumann C, Hetzel M, Babiak AJ, Hetzel J, Merk T, Wibmer T, Lepper PM, Krüger S. Endobronchial tumor debulking with a flexible cryoprobe for immediate treatment of malignant stenosis. J Thorac Cardiovasc Surg. 2010; 139:997-1000 